\title{
ARE YOU RECEIVING?
}

\author{
Out in the cold.
}

\section{BY REBECCA BIRCH}

\section{Galactic Standard Date: 11657.3}

Planetfall successful. Atmosphere breathable, as anticipated from earlier analysis. Base establishment under way, following standard protocol. Work is slow, given we're a five-person crew, but no unanticipated challenges yet reported.

Landscape is surreal. Frozen drifts and billows, like snow back home, but when you look just off of straight there are rainbow spectra dancing in the crystals. Winds are constant. Science Tech O'Malley reported hearing voices when she went outside to set up the solar panels, but the doctor assures me it's just the change in aural input after so long aboard ship. I'm confident initial planetary analysis showing no sign of intelligent life was accurate.

Captain Marjorie Halstone, awaiting confirmation of transmission.

\section{Galactic Standard Date: 11663.8}

Base operational, but not optimal. Solarenergy collectors hampered by constant snow accumulation. Panels have been reoriented to discourage build-up, and shifts have been instituted to clear off what does pile up. We've begun local reconnaissance on foot. Until proper energy levels are established, use of mechanized transport is unfeasible. The snow's spectral light phenomenon seems to intensify during night-time hours. Still awaiting confirmation of original transmission. Are you receiving?

\section{Galactic Standard Date: $\mathbf{1 1 6 7 2 . 5}$}

Despite reorientation of panels, snow accumulation has not decreased, and panel surfaces are sustaining damage. This snow has abrasive properties not previously anticipated. Energy reserves are now below $60 \%$ of recommended. O'Malley continues to report hearing things and is no longer permitted alone surface-side, after attempting to follow the sounds out of range of communications. The doctor has prescribed sensitivity dampeners.

I have not told anyone about the sounds I hear on my own panel-clearing shifts. I prefer to remain unmedicated.

Reconnaissance has been curtailed for $\rightarrow$ NATURE.COM

Follow Futures:

@ @NatureFutures

$f$ go.nature.com $/ \mathrm{mtoodm}$ the moment to focus on snow abatement. Techs Akira and Butler are working to find a reliable countermeasure, but as yet have had no success. Study of atmospheric data shows no sign of any foreseeable change in weather patterns. If no solution is found, I'm afraid I'll be forced to order the termination of this mission.

Stand ready to initiate evacuation procedures and please send immediate confirmation of all transmissions.

\section{Galactic Standard} Date: $\mathbf{1 1 6 7 7 . 2}$

Butler is gone.

We didn't know he was missing until he failed to return from his night-time clearing shift. I attempted to track him, but the colours in the snow hid any footprints, and the farther I got from base... Well, up to this point, I believed the sounds I was hearing were environmental, but now I swear there are words...

Belay that last bit. No, Doctor, I don't require any dampeners. See to O'Malley. She and Butler were close. Please shut the door behind you.

Energy reserves have dipped below $40 \%$. O'Malley is begging to go after Butler, even with an increased dosage of dampeners. The doctor has been drafted into panel maintenance, over his objections. We can't risk letting O’Malley outside again.

Captain Halstone requesting immediate evacuation. Before we lose another.

\section{Galactic Standard Date: $\mathbf{1 1 6 8 0 . 2}$}

Dampeners weren't enough. This morning, O'Malley vanished. Left during my shift and I never saw her. Never heard her. Just those damn lights. I see them on the backs of my eyelids whenever I close them. Akira says he hasn't had more than three hours of sleep in the past two days. I'm not much better off. As for the doctor, he won't talk about the lights. Won't talk about anything. I saw him dosing himself with dampeners, though he claims he doesn't hear the voices.

Power reserves at $15 \%$, well below emergency levels. Both Akira and I have triple-checked communication mechanics. Everything is in working order. Why aren't you responding? Send help now. Please.

\section{Galactic Standard Date: 11682.2}

Found the doctor dead in his bunk this morning of apparent dampener overdose. Energy reserves at 3\% and falling. The cryochamber won't last once they power's gone, so we've buried him in the snow just outside the exterior hatch. His family would wish to have his remains, if anyone should hear this message.

Akira thinks the voices may be originating from a point southwest of base. Remaining here is no longer an option. If there's something else alive out there and we can find it, then maybe we have a chance.

This will be the last communication.
We stagger together through a changed landscape. The snow-light is no longer a mosaic of scattered crystal prisms. Instead, a bright rainbow band spreads across the drifts, leading us southwest. I wouldn't believe it if Akira didn't see it, too. Our feet sink in with each step down the golden path in the centre, and we cling to each other for support.

The voices are clear now, rising up out of the snow. Captain Halstone, abort landing. Unexplained phenomenon detected planetside. Repeat, abort landing. Please confirm.

My own voice, like a dream. Awaiting confirmation of transmission... Are you receiving?

I hear O'Malley, too, and Butler. You're almost here, Captain. Just a little farther. Akira, we're so glad you're coming.

Just ahead, the rainbow narrows until it vanishes in a pool of silver light. Two familiar forms stand with arms outstretched, their bodies rimmed with kaleidoscopic auras.

Akira squeezes my arm. We head for the light. I don't know what's on the other side, and I don't know if we'll ever return, but I'm telling the wind our tale, hoping it will sing until someone comes after us. Someone who can bring the story home.

Ready, Akira? Let's go.

Rebecca Birch lives in Seattle and has been published in markets including the Grantville Gazette, Abyss \& Apex and Penumbra. Find her online at www.wordsofbirch.com. 